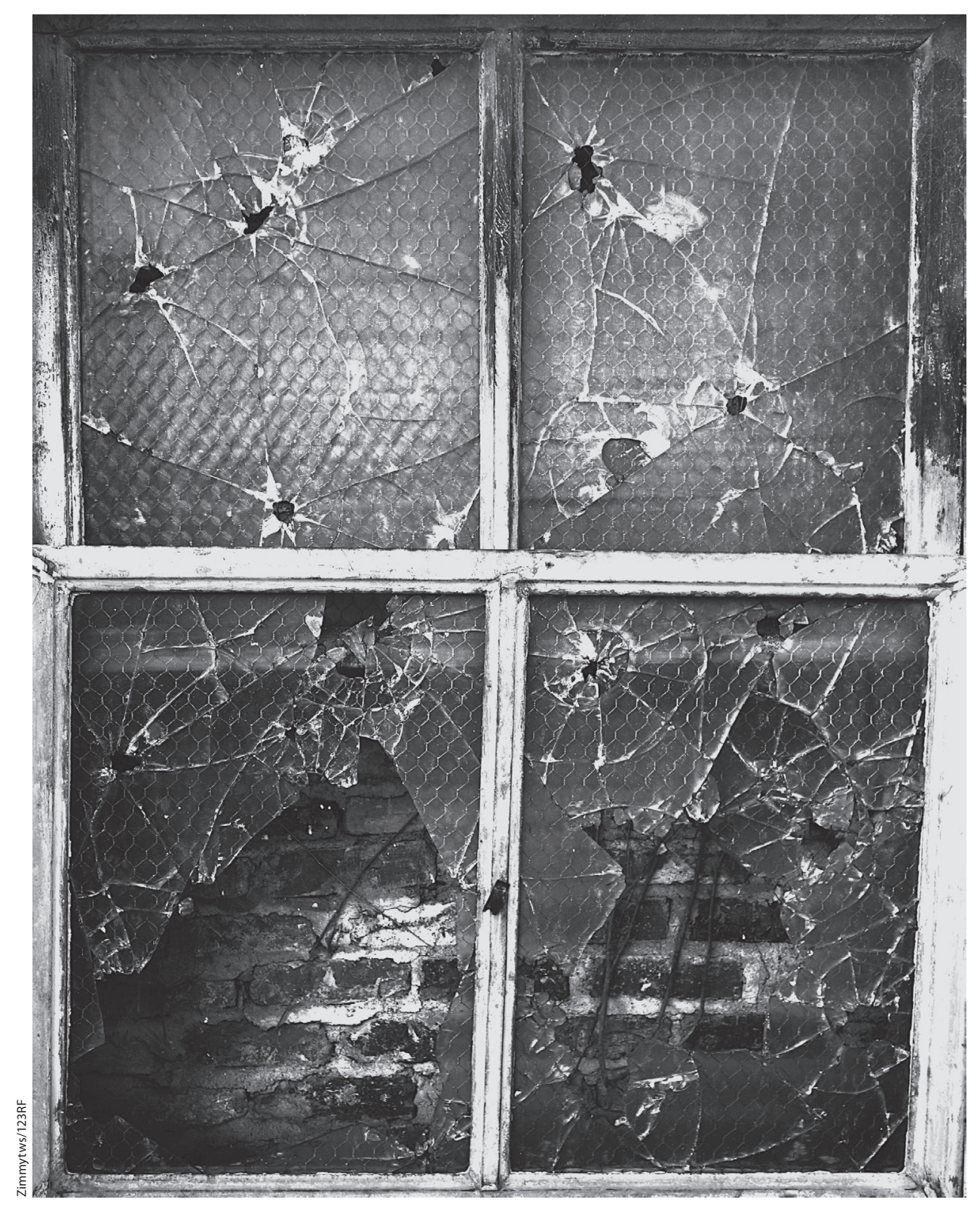

\title{
Os jovens e a criminalididade em Mato Grosso do Sul
}

Giovanni França 


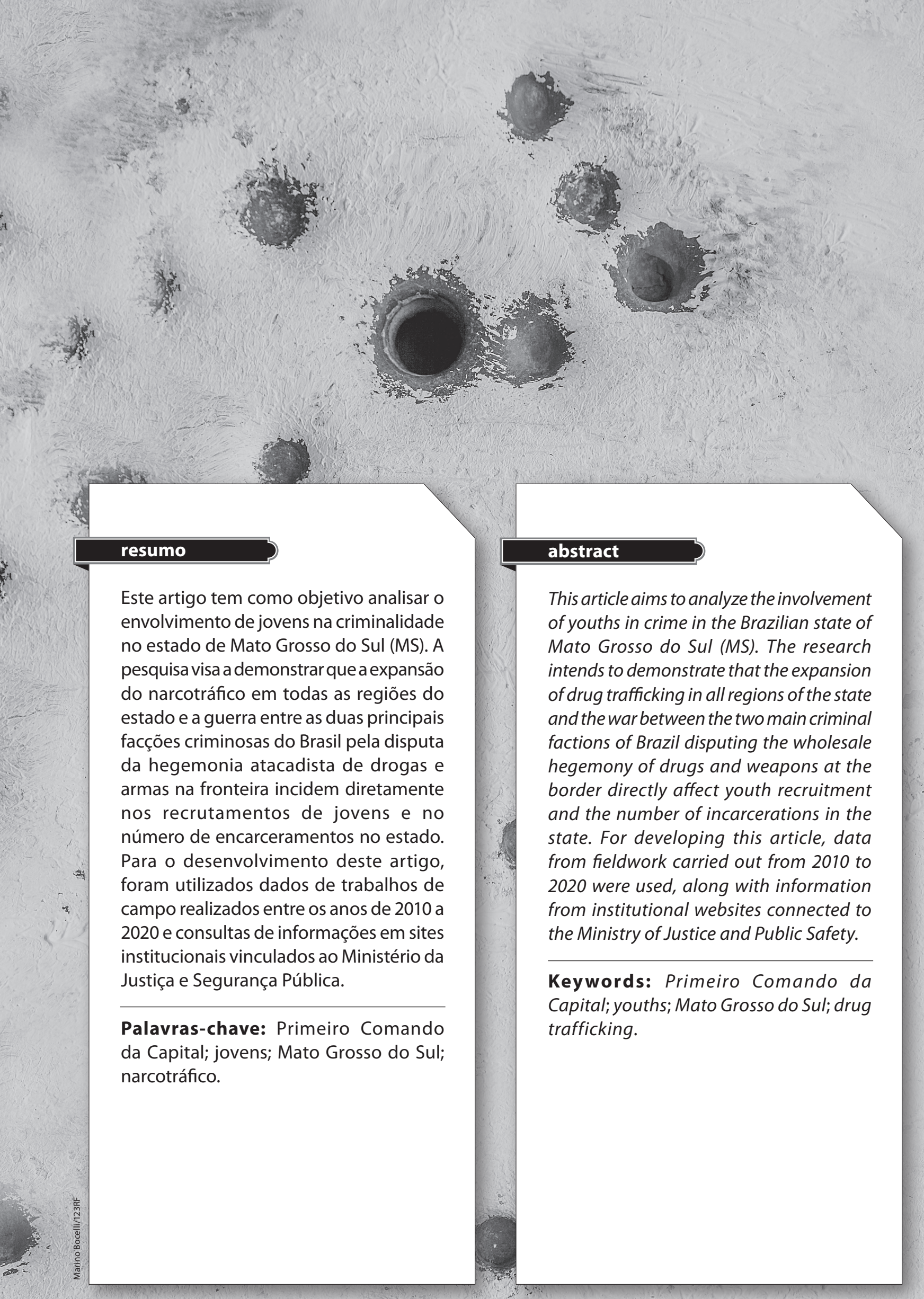




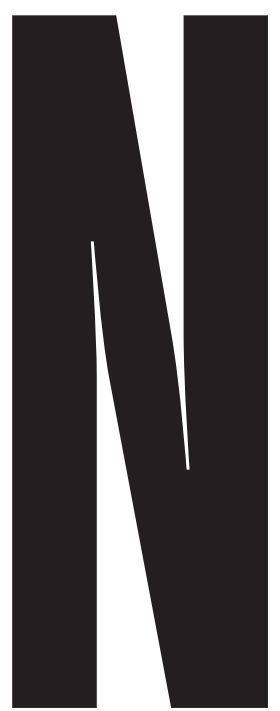

o Brasil, nas últimas décadas, o tráfico de drogas, a criminalidade violenta, o aumento do encarceramento entre os jovens, em sua maioria pardos/ negros, de regiões periféricas, com baixa escolaridade, evidenciaram-se um enorme abismo social construído na sociedade brasileira ao longo de séculos de história.

É importante ressaltar que o crescimento da violência está intrinsecamente atrelado a diversos fatores locais. De fato, o aumento da criminalidade nos últimos 20 anos está amplamente ligado ao crescimento do mercado de drogas ilegais e à expansão dos comandos criminais brasileiros para todas as localidades do país, uma vez que "as drogas financiam as armas e estas intensificam a violência associada às práticas criminosas, expandindo seu número e suas modalidades" (Soares, 2004, p. 2).

A expansão das facções criminosas brasileiras trouxe novos desafios para o geren- ciamento da segurança pública nacional à medida que as extensões da atuação dessas organizações criminosas ultrapassam fronteiras (Oliveira \& Guimarães, 2018). Essas atividades ilegais trazem a reboque, em suas redes, postos de trabalho que vão muito além das tradicionais configurações, baseados na militarização do território e confronto direto contra facções rivais e agentes de segurança pública (Oliveira, 2013).

Telles (2010), ao refletir a respeito da inserção de trabalhadores em atividades criminosas, demonstrou que as transformações do mundo do trabalho em escala global, aliadas à precarização do trabalho formal, diminuição da capacidade de compra e ganhos irregulares, fazem com que essas pessoas sejam forçadas a se utilizar de uma série de redes sobrepostas entre o legal e o ilegal, para suprir suas necessida-

GIOVANNI FRANÇA é doutorando em História pela Universidade Federal da Grande Dourados (UFGD) e pesquisador do Observatório da Violência e Sistema Prisional da Universidade Federal de Mato Grosso do Sul (UFMS). 
des financeiras, sem ter compromisso com as atividades ditas ilícitas.

O crescimento dessa atividade criminal, a precarização do trabalho, a baixa escolarização e o desemprego têm implicações diretas no número de pessoas que acessam esse tipo de trabalho ilícito, de forma transitória ou ainda como meio de vida. A facilidade com que os jovens, com pouca formação escolar e maior vulnerabilidade social, ingressam nas atividades do tráfico de drogas e nos mercados ilegais que gravitam em torno destas (roubos e furtos) é evidente em face do número crescente de pessoas presas por esse tipo de delito no estado do Mato Grosso do Sul.

Este artigo é fruto de trabalho de campo realizado na cidade de Corumbá, tendo sua ampliação com o projeto Segurança Pública nas Fronteiras em vários municípios do estado do MS, incluindo ainda a cidade de Campo Grande, capital do estado. Dessa forma, para elaboração deste artigo, foram analisados alguns aspectos relacionados ao narcotráfico, encarceramento e facções criminosas e suas consequências nefastas para os jovens do estado de Mato Grosso do Sul.

\section{REDES ILEGAIS: ALGUMAS DINÂMICAS CRIMINAIS DE MATO GROSSO DO SUL}

Nos últimos anos, Mato Grosso do Sul converteu-se em uma das principais portas de entrada de drogas ilícitas para o Brasil. O estado faz fronteiras com dois dos principais países produtores de maconha (Paraguai) e cocaína (Bolívia). A proximidade do estado com os grandes centros brasileiros e sua malha viária bem organizada e relativamente conservada contribuem logisticamente para a formação de diversas redes criminais ao longo de décadas.

Segundo o relatório de Segurança Pública nas Fronteiras (2016), ao menos nove cidades são portas de entrada dessas mercadorias ilícitas: Corumbá, Paranhos, Ponta-Porã, Bela Vista, Sete Quedas, Antonio João, Amambaí, Coronel Sapucaia e Caracol. Outras cidades são usadas como ponto de apoio para distribuição de drogas para demais localidades, a exemplo de Dourados. É importante ressaltar que essas redes correspondem a configurações locais do crime, e quando analisamos as áreas de fronteira, as estruturas dessas organizações estão pautadas em práticas fronteiriças cotidianas e transnacionais entre os agentes que operam os negócios. Essas dinâmicas locais criam diversos mecanismos de ações mais ou menos organizadas para o envio de drogas para outras localidades.

Desde o ano de 2019, foi colocado em prática pelo governo federal o Programa Vigia, tendo como principal objetivo conter a entrada de drogas, armas e contrabando de outras mercadorias na faixa de fronteira brasileira. O braço principal desse programa é a Operação Hórus, que reúne as diversas forças de segurança situadas nos respectivos estados brasileiros que fazem fronteiras com outros países ${ }^{1}$ (MJ, 2020). Essa operação vem logrando êxito, especialmente nas apreensões de drogas em todos os estados, inclusive em MS.

1 Disponível em: https://www.gov.br/mj/pt-br/assuntos/ noticias/vigia-programa-nacional-de-seguranca-nas-fronteiras-e-divisas-completa-um-ano-de-atuacao-com-resultados-expressivos-1. Acesso em: 21/2/2021. 
FIGURA 1

Quantitativo de drogas apreendidas

\begin{tabular}{|c|c|c|c|c|c|c|c|}
\hline $\begin{array}{c}\text { Drogas apreendidas em MS } \\
\text { - em toneladas - }\end{array}$ & 2015 & 2016 & 2017 & 2018 & 2019 & $\begin{array}{c}2020 \\
\text { (até Nov) }\end{array}$ & $\begin{array}{c}\text { Total } \\
\text { (toneladas) }\end{array}$ \\
\hline Cocaína e Derivados & 5,3 & 4,4 & 3,9 & 2,6 & 5,7 & 3,4 & 25,3 Ton \\
\hline Maconha e Derivados & 273,8 & 291,4 & 37,1 & 336,5 & 363,8 & 704,4 & $2.347,0$ Ton. \\
\hline Total & 279,1 & 295,8 & 381,0 & 339,1 & 369,5 & 707,8 & 2.372,3 Ton. \\
\hline
\end{tabular}

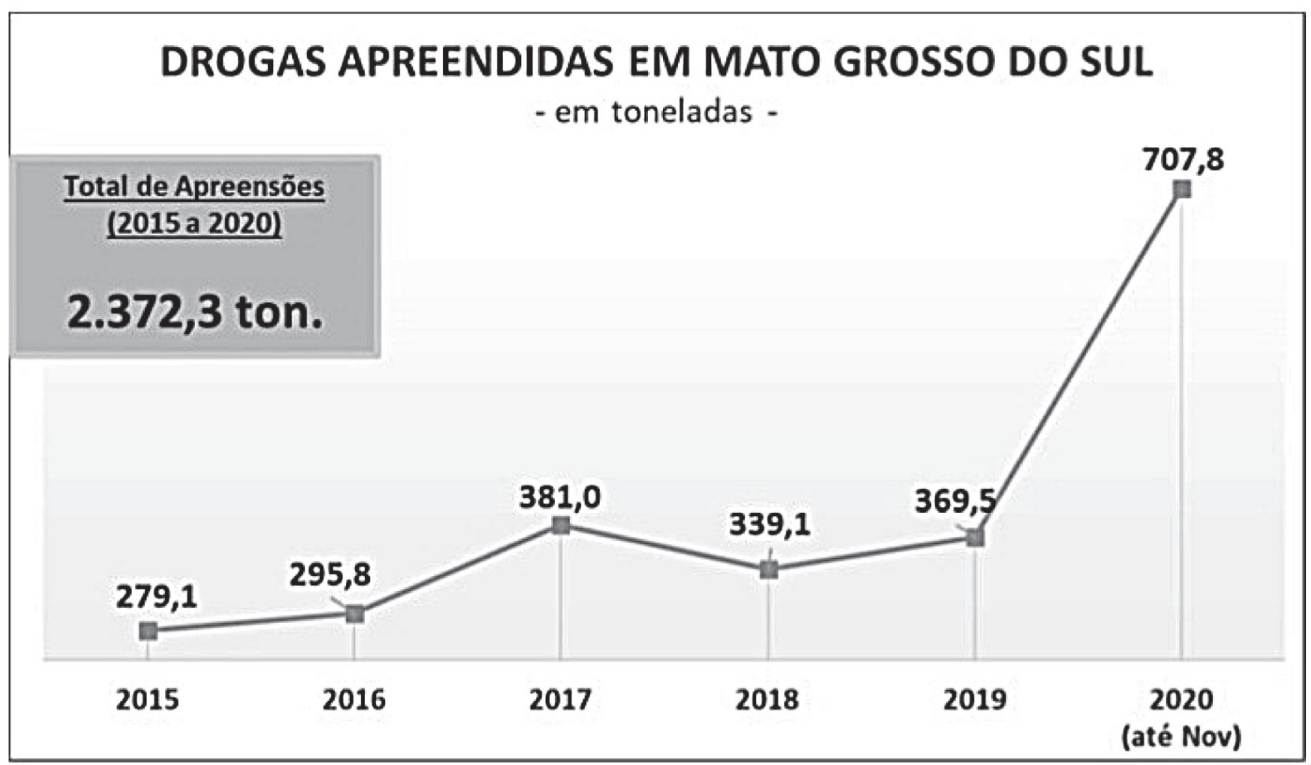

Fonte: Sejusp/MS

No ano de 2020 houve aumento no fluxo de apreensões de drogas no estado. Até novembro de 2020, as apreensões somavam mais de 707 toneladas de drogas, um aumento de $103 \%$ comparado ao ano anterior, no qual foram apreendidas 348 toneladas, como podemos observar na Figura 1.

Do total de drogas apreendidas pelas forças de segurança do estado, a maior apreensão foi de maconha, com mais de 693 toneladas, seguida de drogas sintéticas, com 11 toneladas, depois cocaína, com 2,3 toneladas, pasta base com uma tonelada, haxixe, 341,1 quilos, e crack, 36,6 quilos (Sejusp/MS, 2021). Segundo a Secretaria de Segurança de MS, um dos fatores que mais contribuíram para esse recorde foi o aumento do consumo devido à pandemia de covid-19².

Essa previsão do aumento de consumo de drogas no Brasil se concretizou nos meses iniciais de 2021, em que as forças de segurança do estado já haviam apreendido mais de 43,3 toneladas de drogas, um aumento de $336,5 \%$ em relação ao mesmo mês do ano de 2020 (Sejusp/MS 2021). Nesse contexto,

2 Disponível em: http://www.ms.gov.br/apreensoes-de-drogas-batem-recorde-em- mato-grosso-do-sul-e-ultrapassam-707-toneladasem2020/\#: :text=Balan\%C3\%A7o\%20 divulgado\%20pela\%20Secretaria\%20de,em $\% 20$ Mato\%20Grosso\%20do\%20Sul. Acesso em: 21/2/2021. 
outros mercados ilegais que gravitam em torno do narcotráfico tomam forma e incidem nos índices da criminalidade no estado.

Em nível de varejo, a ação de furtos e roubos - em especial os celulares smartphones - converteu-se em uma poderosa moeda de troca por drogas nos pontos de venda (bocas). O destino desses aparelhos é diverso, em especial no abastecimento do mercado crescente de manutenção de celulares, ou, ainda, utilizados em ações criminosas dentro e fora dos presídios.

No atacado, a subtração de veículos automotivos, que na sua maior parte tem procedência de outros estados da federação, em especial carros e carretas, e golpes do seguro são utilizados como ligação importante na cadeia estrutural do narcotráfico, seja para trocar por drogas nos países produtores, seja para utilização no transporte de cigarros, drogas, armas e munições. Assim, o governo do estado, desde 2011, tem intensificado as operações contra esse tipo de crime e, segundo o Sindicato das Seguradoras de $\mathrm{MS}^{3}$, no ano de 2020, o estado tornou-se o primeiro nos índices de recuperação de veículos automotivos furtados/roubados no Brasil (SINDSEG/ $\left.\mathrm{MS}^{4}, 2020\right)$, demonstrando que o estado também se constituiu como rota de receptação nesse tipo de crime.

3 Em números absolutos, o Paraná é o quinto estado do Brasil com maior número de casos de furtos e roubos de veículos $(16.622)$ e apresentou índice de recuperação de $53,91 \%$, um pouco acima da média nacional de $49,93 \%$. Mato Grosso do Sul é o $21^{\circ}$ estado em número de veículos furtados ou roubados (3.346) e apresentou o melhor índice de recuperação do Brasil, 80,90\% (SINDSEG/MS, 2020).

4 Disponível em: https://sindsegprms.org.br/mato-grosso-do-sul-tem-o-melhor-indice-de-recuperacao-de-veiculos-do-brasil/. Acesso em: 21/2/2021.

\section{O PRIMEIRO COMANDO DA CAPITAL - PCC/MS}

Denota-se que, apesar dos esforços do Estado brasileiro em conter o avanço de diversas práticas criminais, a economia do narcotráfico continua avançando a passos largos. Isso se deve ao aumento da atuação dos comandos criminais no MS e, principalmente, nas suas fronteiras.

As duas principais facções criminais brasileiras que atuam no estado são o Primeiro Comando da Capital (PCC) e o Comando Vermelho (CV), que até o ano de 2016 conviveram de forma pacífica. Todavia, nos últimos 20 anos o PCC ganhou força em todas as regiões do Brasil, inclusive no estado de MS, expandindo-se para todas as regiões do estado, conforme observado no informativo da divisão por regiões feita pela facção, disponibilizado pelo Ministério Público de São Paulo na Operação Echelon ${ }^{5}$, de 2018. O crescimento do poder dessa facção nos presídios do estado de Mato Grosso do Sul teve como marco a megarrebelião de 2006, na qual, seguindo o "salve geral" vindo de São Paulo, naquele mês de maio, os presídios de Corumbá, Campo Grande, Dourados e Três Lagoas aderiram à rebelião de repercussão nacional (Oliveira, 2013).

A expansão do PCC nos presídios de MS teve como ponto de partida as alianças e dívidas morais entre o presídio e a rua, edificada entre trocas de favores e proteção pessoal/grupal que possibilitaram o

5 Disponível em: http://www.mpsp.mp.br/portal/page/ portal/noticias/noticia?id_noticia=18770003\&id_grupo $=118$. Acesso em: 21/2/2021. 


\section{Geografia do PCC em MS}

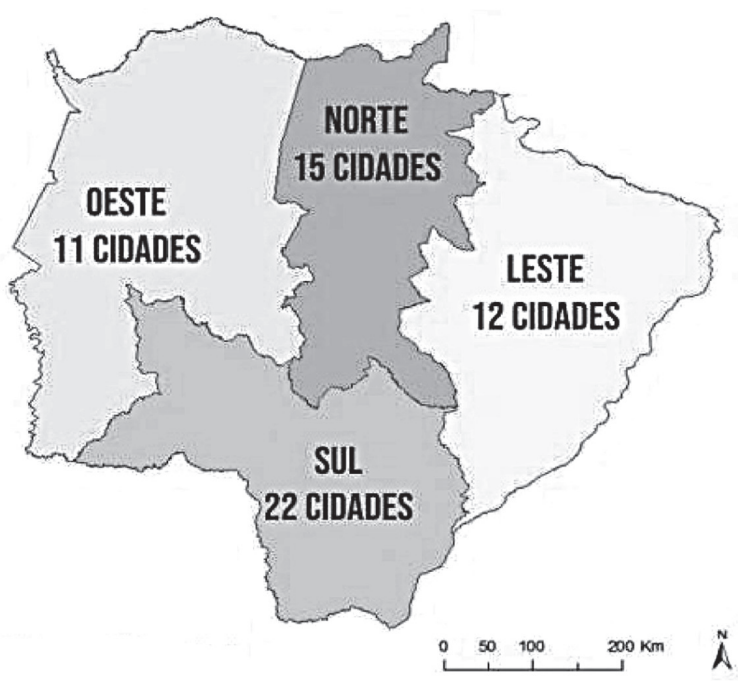

Fonte: Operação Echelon

acesso e ampliação do poder dessa facção em todos os presídios do estado (Oliveira \& Guimarães, 2018).

A Figura 2 demonstra como o PCC gerencia suas operações e sua expansão no estado ${ }^{6}$, a partir do aumento de batismos feitos dentro e fora dos presídios.

A divisão geográfica do estado em áreas de atuação do PCC faz parte de um projeto de alcance de influência em todas as cidades a partir da formação de diversas células de atuação. Assim, o assassinato de Jorge Rafaat em 2016 pôs fim a acordos feitos entre essas duas facções, desencadeando confronto direto pelo controle das rotas do tráfico de drogas e armas no estado de MS.

Antes do início da guerra entre essas duas organizações criminosas, o mercado ilegal do narcotráfico em MS já mostrava seus efeitos há tempos, principalmente nos índices de encarceramento, conforme evidenciado no projeto Segurança Pública nas Fronteiras - Eixo Central (2014) e pelo Mapa da violência. Nos trabalhos de campo realizados para esse projeto, verificou-se o recrutamento de jovens para as fileiras das organizações "independentes" ou das facções já mencionadas (Enafron, 2016). No geral, os chamados "moleques apetitosos" são jovens de alta vulnerabilidade social que entram no mundo do crime como soldados, desempenhando pequenas funções (Oliveira, 2013). Dependendo de sua idade, determinadas funções são tomadas e suas obrigações são colocadas em prática na forma de "missão". Esses "moleques ape-
6 Disponível em: https://www.campograndenews.com. $\mathrm{br} / c i d a d e s / n o-m a p a-d o-p c c-m s-e-u m-d o s-e s t a d o s-$ -onde-faccao-domina-o-crime. Acesso em: 19/1/2021.
7 Categoria utilizada pelo PCC para demarcar os jovens que estão no mundo do crime e querem se tornar membros da facção. 
titosos" atuam na linha de frente dessas organizações executando o que for mandado. São esses jovens que, ao serem presos pela polícia, fazem ecoar no sistema carcerário o enorme problema social que o país vive na atualidade: o encarceramento em massa.

\section{DADOS DE ENCARCERAMENTO DE JOVENS EM MATO GROSSO DO SUL}

$\mathrm{O}$ indicador de encarceramento no Brasil nos últimos dez anos cresceu em média $7,14 \%$ ao ano. O estado com maior população carcerária é São Paulo, com aproximadamente 229 mil presos. O estado de Mato Grosso do Sul é o $12^{\circ}$ dos estados brasileiros em quantitativos carcerários, com aproximadamente 17.578 pessoas encarceradas. A Figura 3 mostra a população carcerária brasileira segundo os dados do
Levantamento Nacional de Informações Penitenciárias (Infopen, 2019).

Ao analisar as estatísticas do sistema carcerário nacional, pode-se concluir que quase metade da população carcerária do Brasil tem entre 18 e 29 anos de idade. "Como demonstrado, a clientela carcerária é constituída, em sua maioria, por homens negros jovens, moradores de regiões periféricas e que já se encontravam excluídos anteriormente das demandas de consumo e com pouco acesso às políticas sociais" (Narciso Torres, Bessa \& Torres, 2018, p. 96.)

De acordo com o Infopen (2019), no que diz respeito à etnia e à cor das pessoas privadas de liberdade, 46,27\% são pardos, $17,37 \%$ são negros, $35,48 \%$ são brancos, $0,22 \%$ são indígenas e $0,22 \%$ são de pele amarela. O porcentual de mais de $50 \%$ de pessoas pardas/negras encarceradas evidencia a seletividade punitiva

\section{FIGURA 3}

População prisional por faixa etária no Brasil (período de julho a dezembro de 2019)

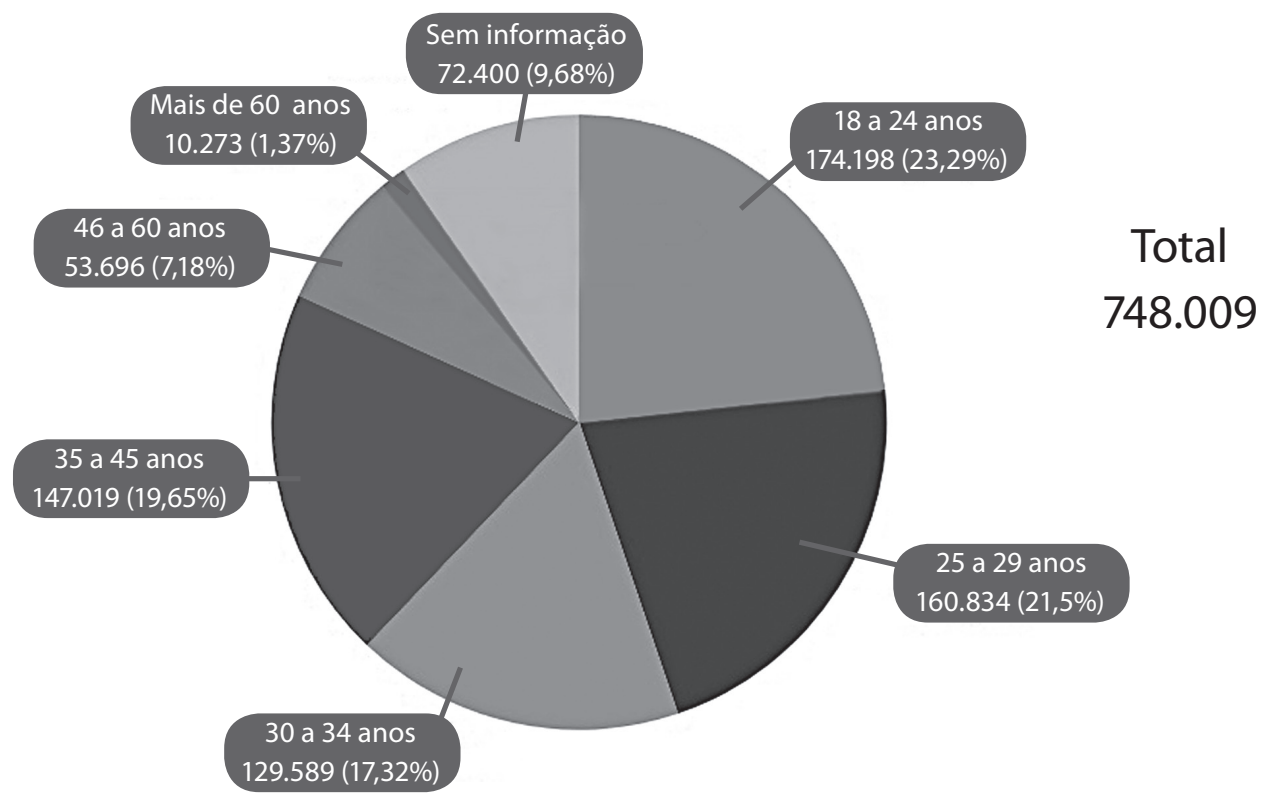

Fonte: Infopen 
das instituições de segurança e de justiça brasileiras, que estigmatizam os jovens negros de regiões periféricas (Narciso Torres, Bessa \& Torres, 2018).

Os crimes hediondos e equiparados em número de ocorrências são, em primeiro lugar, o tráfico de drogas, com 41,65\%, seguido por homicídio qualificado, com $28,74 \%$, latrocínio, com 6,94\%, dentre outros. Mato Grosso do Sul não foge à regra nacional, como se pode observar na Figura 4.

Quase $50 \%$ das pessoas privadas de liberdade têm entre 18 e 29 anos de idade, $51,98 \%$ são pardas, $10,31 \%$ são negras, $34,64 \%$ são brancas, $1,77 \%$ são indígenas, $0,56 \%$, de etnia amarela e $0,74 \%$ não informado. Dessa totalidade, $75,86 \%$ não conseguiram concluir o ensino médio e apenas $1,02 \%$ têm ensino superior completo.
Na tipificação de crimes hediondos e equiparados com mais de $50 \%$ no estado de MS (Figura 5), o tráfico de drogas ocupa a primeira colocação, seguido de latrocínio e homicídio qualificado, dentre outros. No quesito crimes violentos, na primeira posição está roubo simples, com 27,65\%, depois roubo qualificado, com $24,88 \%$, seguido de homicídio simples, com 12,31\%, entre outros.

Esses dados são alarmantes, com seus reflexos nas Unidades Educacionais de Internação (Uneis). Já no ano de 2009, Brioli demonstrou que no total de jovens de 15 a 18 anos cumprindo medidas socioeducativas nas Uneis, os principais atos infracionais cometidos eram: a) formação de quadrilha; b) homicídios; e c) tráfico de drogas. Pelo menos $60 \%$ deles já eram reincidentes e 50\%, reincidentes no mesmo tipo de delito. Os

\section{FIGURA 4}

População prisional total e por faixa etária no estado de MS (período de julho a dezembro de 2019)

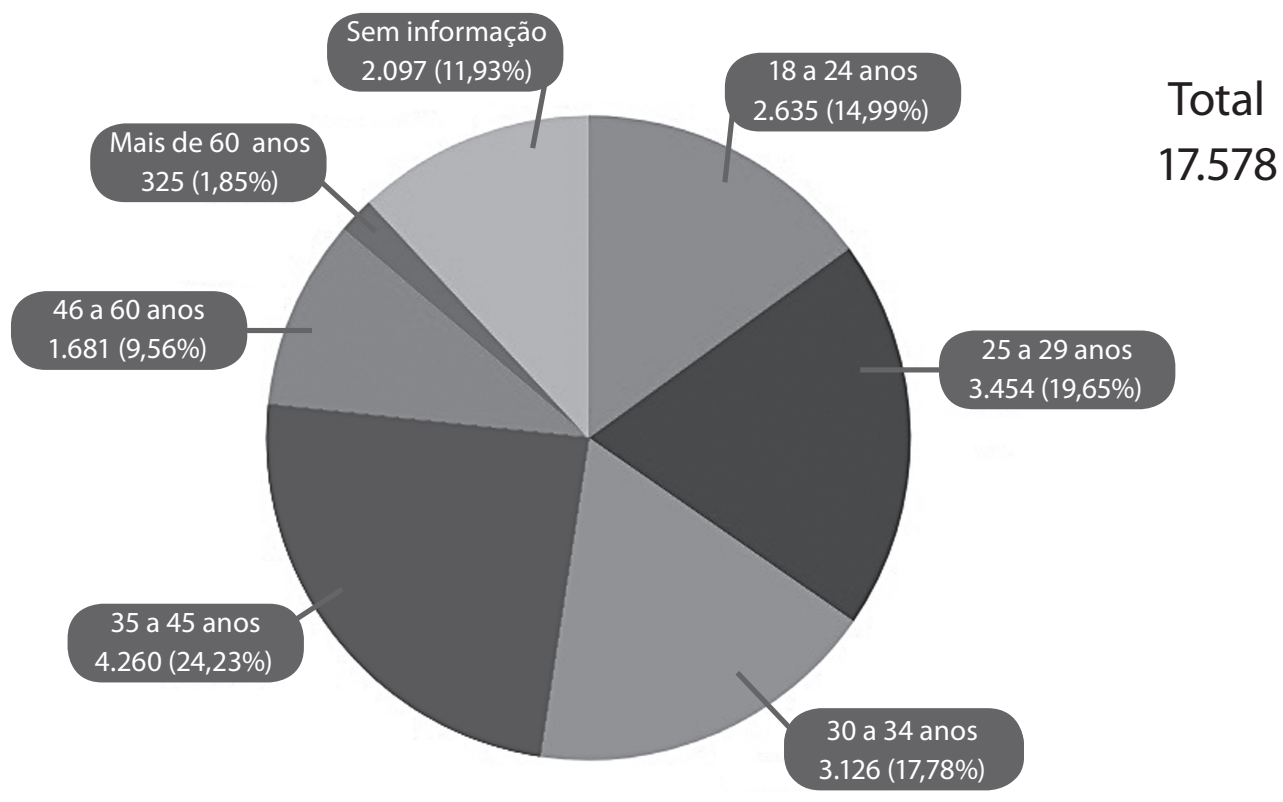

Fonte: Infopen 


\section{FIGURA 5}

Crimes hediondos e equiparados no estado de MS (período de julho a dezembro de 2019)

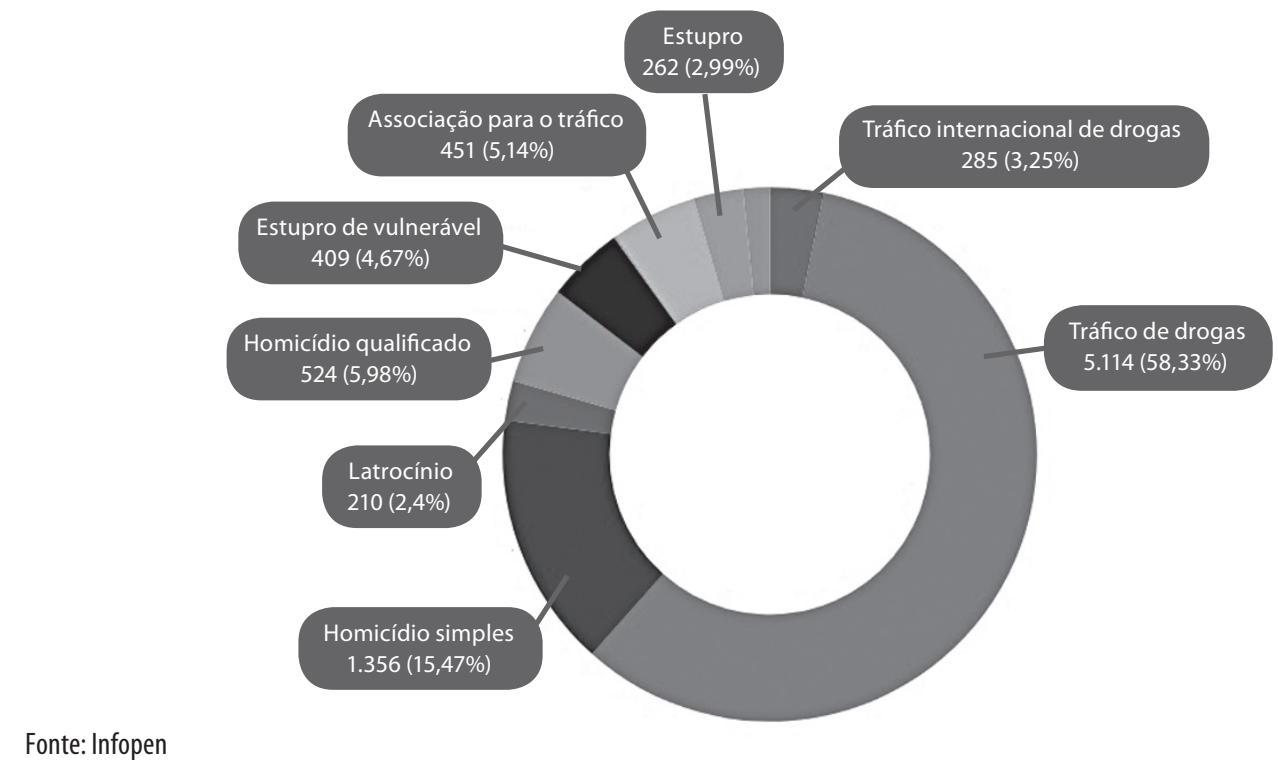

níveis de escolaridade variavam entre $12 \%$ de analfabetos e $50 \%$ que não concluíram o ensino médio.

No ano de 2017, outros índices foram divulgados a respeito de menores envolvidos em crimes no estado. Entre 2013 e 2017 dobrou o número de jovens que cumprem medidas socioeducativas nas Uneis/ MS. De um total de 60 jovens que cumpriam medidas socioeducativas em 2013, no ano de 2017 esse número passou para 246 adolescentes. Dessa feita, os principais atos infracionais praticados por esses adolescentes foram: $94 \%$ por roubo; $60 \%$, tráfico de drogas; e 44\%, homicídio e outros crimes diversos. Nesse diapasão, os perfis desses adolescentes continuam os mesmos apontados por Brioli (2009), quais sejam, adolescentes com baixa escolaridade oriundos de famílias desestruturadas.

Levando em consideração que no estado de MS existem atualmente dez Unidades
Educacionais de Internação, distribuídas em cinco cidades de todas as macrorregiões do estado (inclusive três dessas instituições estão localizadas na faixa de fronteira: unidades de Corumbá, Ponta-Porã e Dourados), pode-se concluir que a disseminação dessas práticas ocorre também na faixa etária entre 15 e 18 anos, como também o envolvimento desses adolescentes com organizações criminosas. Nos últimos anos, aconteceram diversos episódios nessa instituição (Unei), como uso de drogas, assassinatos entre os jovens e torturas perpetradas pelos agentes dentro das unidades, o que foi alvo de diversas denúncias feitas por familiares e pela mídia em geral. Alguns confrontos configuraram-se como disputas envolvendo o mundo do crime e a guerra entre as facções.

Os índices da Sejusp/MS demonstram maior participação desses adolescentes no mundo do crime, que são utilizados na guerra 
entre as facções que ocorrem no estado, apontando que essas disputas já extrapolaram as unidades prisionais, chegando às unidades de internação, evidenciando o uso desses adolescentes como soldados do crime em todas as regiões de MS.

\section{O MUNDO DO CRIME E OS JOVENS DE MS}

A partir de pesquisas realizadas no âmbito do projeto nacional Segurança Pública nas Fronteiras e pelo Observatório da Violência e Sistema Prisional da Universidade Federal de Mato Grosso do Sul (UFMS), foram traçados alguns pontos importantes a respeito da expansão do mundo do crime nas cidades sul-mato-grossenses.

Os noticiários e jornais locais estão repletos de matérias com imagens de jovens que cometeram crimes, variando em grau e intensidade. A respeito desses noticiários, Borges (2014) analisa que essas reportagens, em quase sua totalidade, estão vinculadas a jovens, pobres e periféricos e quase sempre tratados como um problema, pois as reportagens versam sempre sobre a prática de delitos (tráfico de drogas, assassinatos, vandalismo, dentre outros). De acordo com a autora:

"Outro aspecto refere-se à associação da ideia do jovem/adolescente como um problema social, um movimento que em geral está relacionado à localização geográfica onde eles residem. O bairro ou a localidade em que esses sujeitos vivem são enfatizados como espaços de sujeitos ditos violentos por pertencerem às áreas territoriais de maior problemática ou com maior contingente de classes populares e pobres" (Borges, 2014, p. 79).

Para Borges (2014), deve-se ir além da reafirmação de estigmas sociais enraizados na sociedade brasileira frente às transformações sociais vivenciadas. Para a autora, o que também chamou a atenção são os crimes em que esses jovens estão envolvidos, com destaque ao crescimento das atividades ilegais, em especial o tráfico de drogas, como vetor importante para a participação desses jovens em práticas delitivas.

Tendo em vista esses aspectos, para Reis (2013), a questão da criminalidade não é algo estático, vinculada a apenas uma classe social, mas a mídia tem papel fundamental no processo de seletividade e de marcadores sociais - jovens negros e de bairros periféricos. De acordo com Feltran (2008, p. 180):

"O 'mundo do crime' expande-se em torno do mercado da droga e de armas e interfere nas dinâmicas sociais. A sociabilidade que se cria em torno destas dinâmicas está muito relacionada às mudanças do capitalismo: 'dinâmico, flexível, imagético, global'. Bens de consumo e dinheiro circulam de forma rápida, o consumo está dissociado da renda e a flexibilidade para a obtenção do crédito gera o endividamento dos indivíduos, assim como ocorre na economia popular comum".

Assim, ainda segundo Feltran (2008), o mundo do crime, para muitos jovens em situação de vulnerabilidade social, torna-se mais atrativo que o mercado formal de trabalho devido ao "acolhimento" que essas atividades lhes proporcionam. As transformações no mundo do trabalho, baixos salários, baixo nível de escolaridade e desestruturação 
familiar solapam a ideia de ascensão social abrindo caminho para a entrada no mundo do crime. Nesse sentido, Pereira (2018), ao analisar o envolvimento de jovens de 15 a 18 anos com o mundo do crime na região de Dourados, observa a relação estreita entre vulnerabilidade social e expansão do mundo do crime nas periferias da cidade, atrelada aos comandos criminais e ao tráfico de drogas. Segundo a autora, "[...] a imagem do adolescente traficante de drogas como o 'vagabundo' que escolhe o crime estimula a pensá-lo como o inimigo público, o inimigo da sociedade e, assim, torna-se legítimo não o tratar como sujeito de direitos, inclusive o Estado" (Pereira, 2018, p. 107).

Para Oliveira (2013), os jovens (ou os "meninos apetitosos") tornaram-se importantes agentes dessa mudança na ordem local do crime com a expansão dos comandos criminais, que têm como foco o recrutamento deles, principalmente depois do início da guerra entre o PCC e o Comando Vermelho. Esses jovens tornam-se os "soldados da facção", a linha de frente das atividades. Tais indivíduos desenvolvem diversos tipos de funções, a depender de sua idade, para realizar as missões. Em situação de entrada no mundo do crime, têm pressa em conseguir certo status e por isso são os mais seduzidos com as promessas desse meio.

Segundo o relatório do Enafron (2016), constatou-se o aumento de jovens nas regiões de fronteira de MS envolvidos de alguma forma com o narcotráfico. Eles desempenham os mais diversos postos dentro dessas redes. O envolvimento com furtos/roubos de veículos automotivos, venda e transporte de drogas e armamentos (como mulas dessas redes) são atividades recorrentes observadas pelo relatório.
O que nos chama a atenção nesse contexto é o envolvimento dos jovens nos tribunais do crime, sendo vítimas ou algozes. Esses tribunais tornaram-se recorrentes e são noticiados cotidianamente nos jornais locais em várias cidades do estado. Os vídeos divulgados pelas mídias sociais mostram jovens praticando atos bárbaros contra integrantes de outra facção visando à disseminação do medo, vingança e demonstração de poder. Esses tribunais vêm sendo alvo de investigações da polícia ${ }^{8}$, que, nos últimos anos, interrompeu diversos julgamentos prendendo diversas pessoas 9 .

É importante destacar que tais reverberações na vida social das ruas das cidades de Mato Grosso do Sul modificaram formas de "proceder" dos jovens que se filiam ao PCC, produzindo subjetivamente comportamentos e identidades para além da família e vizinhança. Assim, ao se filiarem ao "Comando", adquirem prestígio nas ruas.

\section{DINÂMICAS CRIMINAIS EM CURSO NO ESTADO DE MS}

A morte de Jorge Rafaat no ano de 2016 foi repercutida pela imprensa nacional, que atribuiu o assassinato ao PCC. De fato, esse assassinato deu início à guerra entre as duas grandes facções brasileiras (PCC e CV). Os jornais locais, em especial

8 Disponível em: https://www.midiamax.com.br/policia/2020/operacao-contra-o-pcc-mira-em-ordens-de-tribunal-do-crime-que-partem-de-ms. Acesso em: 19/1/2021.

9 Disponível em: https://www.midiamax.com.br/tag/ tribunal-do-crime. 
os de maior circulação no estado ${ }^{10}$, a todo momento veiculam notícias - na maioria das vezes, de forma sensacionalista - a respeito da atuação e do conflito entre esses dois grupos, inclusive atribuindo a diminuição de homicídios na capital Campo Grande à expansão do PCC na cidade, como facção dominante. Não excluímos essa possibilidade, mas preferimos analisar a criminalidade do estado de MS a partir das realidades locais e não apenas como refratária de outras localidades do país. Entendemos que existem relações entre a criminalidade do estado e a de centros urbanos da Região Sudeste que precisam ser analisadas.

A partir dos trabalhos de campo desenvolvidos no estado, podemos traçar alguns cenários sobre a criminalidade no estado do MS.O primeiro cenário é que a dinâmica da criminalidade obedece a construções históricas de suas respectivas localidades citadinas. Dessa forma, não se deve ignorar a influência e o poder das dinâmicas locais do crime e seus efeitos na associação e resistência à expansão dos comandos criminais brasileiros no estado.

O segundo cenário está no fato, pontuado por Torres (2020), de que nem o PCC nem o CV mantêm a hegemonia da criminalidade nos presídios e, portanto, também fora deles. Dessa forma, cita-se como exemplo a cidade de Campo Grande, com os índices de homicídios em queda. Não se ignora que o PCC possa ter algum tipo de influência na diminuição desses índices de homicídios na capital, mas, em contrapartida, os crimes violentos tiveram aumento significativo.
$\mathrm{O}$ que as pesquisas têm demonstrado é o fato de que a dinâmica da criminalidade não obedece apenas às regras das facções criminosas, existem também os chamados "independentes", ou seja, a ordem local do crime antes da entrada das facções. Os "independentes" podem concorrer, "correr junto", ou serem absorvidos por qualquer facção (Oliveira, 2013). Sendo assim, existe um fatiamento dos bairros da capital entre essas forças, além das políticas de segurança pública empregadas na localidade. Esse conjunto de situações acaba tornando a dinâmica local do mundo do crime mais complexa, podendo incidir no quantitativo de homicídios.

No terceiro cenário, não se deve ignorar as configurações do mundo do crime dos países que fazem fronteira com o estado. Essas organizações não são inertes à ação das organizações brasileiras e/ou simplesmente escolhem um lado ou outro lado. Nem sempre só a lealdade aos comandos do lado brasileiro vai prevalecer, existe também a lógica dos negócios, o que torna essas relações instáveis. Dessa forma, no que diz respeito à morte de Rafaat, em 2016, pode estar em jogo o reordenamento da criminalidade local e não necessariamente a hegemonia de um comando.

Podemos citar outro exemplo do início dos anos 2000, a "guerra" na cidade de Coronel Sapucaia entre a família Morel e o Comando Vermelho. O resultado desse acontecimento não tornou o $\mathrm{CV}$ uma facção hegemônica nessa cidade, mas pulverizou os espaços para os negócios do crime ${ }^{11}$.

11 Trabalho de campo realizado na cidade de Coronel Sapucaia a partir de diversas entrevistas individuais e grupos focais, pelo projeto Segurança Pública nas

Fronteiras.
10 Disponível em: https://www.campograndenews.com. br/; https://www.midiamax.com.br/; https://correiodoestado.com.br/. Acesso em: 19/1/2021. 
Outro exemplo emblemático de configurações locais do crime é a cidade de Corumbá, na fronteira com a Bolívia. O mundo do crime na localidade tem fortes relações no tráfico de cocaína, que ao longo de décadas permaneceu pulverizado em núcleos familiares, no varejo e no atacado. Através das pesquisas desenvolvidas, observou-se a atuação do CV na localidade desde a década de 1980, e do PCC, a partir de 2006. Nenhuma das facções alcançou a hegemonia, permanecendo a lógica dos grupos “independentes". Nos últimos anos, o PCC tem almejado agrupar bairros na cidade sob seu controle, não obtendo o sucesso esperado. Apesar disso, o PCC via presídio - vem ganhando força a partir de associações do "correr junto" com a lógica local do crime (Oliveira, 2013; Oliveira \& Guimarães, 2018).

O quarto cenário, o menos pesquisado, compreende a região leste do estado, onde se encontra Três Lagoas, a principal cidade da região, além de uma "porta de entrada" para o estado de São Paulo. Nos últimos vinte anos, a cidade teve dinâmicas migratórias importantes vinculadas a grandes projetos econômicos com a instalação de diversas indústrias. Para Batista (2008), o crescimento da cidade trouxe diversos problemas sociais, como aumentos dos aluguéis e falta de moradia, além de crescimento da prostituição e do tráfico de drogas.

Por fim, o mundo do crime em Mato Grosso do Sul é complexo, em razão do seu tamanho e do espaçamento entre as cidades, aliado ao fato de o estado fazer fronteira com Paraguai e Bolívia, merecendo assim uma análise mais detalhada e aprofundada a partir de suas realidades, para só então poder-se entender as interligações entre as redes criminais do estado.

\section{CONSIDERAÇÕES FINAIS}

Um dos principais desafios deste trabalho foi demonstrar que o crescimento da atuação das redes do narcotráfico aliado à expansão e às disputas pelo poder de facções criminais do estado do Mato Grosso do Sul tornou-se um fator importantíssimo para novas configurações locais do mundo do crime e o aumento do número de jovens recrutados diariamente para essas fileiras.

De modo algum buscou-se fazer qualquer tipo de associação do tráfico de drogas e da criminalidade com os jovens de bairros periféricos ou de baixa renda, assim, qualquer ligação não pode ser sustentada, uma vez que baseada em estigmas e preconceitos. Esses marcadores sociais, estereótipos e estigmas já são constantemente disseminados pelas mídias de informações jornalísticas locais.

Desde que as pesquisas foram iniciadas sobre o tema da criminalidade na fronteira Brasil/Bolívia, observou-se o papel dos jovens em diversas ações criminosas na localidade. O varejo de drogas mostrou-se um importante catalisador de mudanças nas práticas criminais, onde os jovens figuravam um dos pontos-chave da questão. Essa hipótese é confirmada a partir das pesquisas feitas em mais de 20 cidades pelo projeto Segurança Pública nas Fronteiras.

Os "meninos apetitosos" são aqueles jovens que, na maior parte das vezes, enxergam o mundo do crime como ponte de saída para a falta de perspectivas de 
qualquer tipo de ascensão social. Estes são recrutados como soldados para as fileiras do mundo do crime. Nesse ambiente, esses jovens são "acolhidos", suas despesas mais básicas de sobrevivência familiar são sanadas e os recursos para despesas, com bens de consumo almejados por eles, são bancados e resolvidos pelas facções.

Por fim, vale dizer que são esses jovens que aparecem na linha de frente no mundo do crime, na guerra entre facções, os quais são decapitados e torturados, demonstrando assim o descaso do Estado brasileiro com esses jovens.

\section{REFERÊNCIAS}

ADORNO, S.; SALLA, F. "Criminalidade organizada nas prisões e os ataques do PCC". Estudos Avançados, 21 (61), 2007.

BATISTA, R. L. A geografia da violência: uma abordagem espacial da criminalidade em Três Lagoas - MS. Dissertação de mestrado. Campo Grande, Programa de Pós-Graduação em Geografia da UFMS, 2008.

BORGES, E. V. Adolescentes e jovens nas manchetes dos jornais impressos de Dourados/MS. Dissertação de mestrado. Dourados, Programa de Pós-Graduação em Educação da UFGD, 2014.

BRASIL. Ministério da Justiça. Departamento Penitenciário Nacional (Depen). Levantamento nacional de informações penitenciárias Infopen - janeiro de 2019. Infopen, 2019.

BRASIL. Ministério da Justiça. Segurança pública nas fronteiras: eixo central. Brasília, 2016. BRASIL. Ministério Público. Vigia: programa nacional de segurança nas fronteiras, 2019. BRASIL. Presidência da República. Secretaria Geral da Presidência da República.

Secretaria Nacional da Juventude. Mapa do encarceramento: os jovens do Brasil. Brasília, Presidência da República, 2015.

BRIOLI, P. V. Da exclusão ao sonho: a (re)construção da identidade de adolescentes em Unidade Educacional de Internação (Unei) sul-mato-grossense. Dissertação de mestrado. Três Lagoas, Universidade Federal de Mato Grosso da Sul, 2019.

CAMPO GRANDE. Secretaria Municipal de Educação. Educação preventiva ao uso de drogas. 2015.

FELTRAN, Gabriel de Santis. Fronteiras de tensão: um estudo sobre política e violência nas periferias de São Paulo. Tese de doutorado. Campinas, Instituto de Filosofia e Ciências Humanas da Unicamp, 2008. 
NARCISO TORRES, E.; BESSA, C. ; TORRES, O. "Vidas negras: um panorama sobre os dados de encarceramento e homicídios de jovens negros no Brasil". Revista Trama Interdisciplinar, v. 9, 2018, pp. 86-106.

OLIVEIRA, G. F. Nas bocas da cidade de Corumbá-MS: o comércio de drogas na fronteira Brasil/Bolívia. Dissertação de mestrado. Campo Grande, Programa de Pós-Graduação em Estudos Fronteiriços da UFMS, 2013.

OLIVEIRA, G. F.; GUIMARÃES, C. K. "As relações de reciprocidade e dívidas morais entre o presídio e a rua: A expansão e transnacionalização do Primeiro Comando da Capital (PCC) na fronteira Brasil-Bolívia". Dilemas: Revista de Estudos de Conflito e Controle Social, vol. 11, 2018.

PEREIRA, J. G. O adolescente e o tráfico de drogas na cidade de Dourados: sob uma perspectiva subcultural. Dourados, UFGD, 2018.

REIS, A. F. "Violência e desenvolvimento local: um estudo sobre a criminalidade entre jovens de 15 a 24 anos em comunidades periurbanas de Campo Grande, MS". Interações, v. 14, 2013.

SOARES, L. E. Juventude e Violência no Brasil Contemporâneo. Juventude e Sociedade: Trabalho, Educação, Cultura e Participação. 1a ed., 2004, pp. 130-159.

TELLES, V. S. "Ilegalismos urbanos e a cidade". Novos Estudos, julho/2009, pp. 153-73.

TORRES, E. N. S. A institucionalização da inteligência penitenciária nacional: o combate às organizações criminosas e o caso "Primeiro Comando da Capital (PCC)" nas prisões brasileiras. Rio de Janeiro, ESG, 2020. 